\title{
Exercise enhances creativity independently of mood
}

\author{
Hannah Steinberg, Elizabeth A Sykes, Tim Moss, Susan Lowery, Nick LeBoutillier, \\ Alison Dewey
}

\begin{abstract}
Objectives-It has been widely accepted in the literature that various forms of physical exercise, even in a single session, enhance positive mood. It has also been shown that physical exercise may sometimes enhance creative thinking, but the evidence is inconclusive. Positive moods can favour creative thinking, but the opposite has also been reported and these relations are unclear. There is a large anecdotal literature suggesting that creative people sometimes use bodily movement to help overcome "blocks". The aim of this study was to establish whether post-exercise creative thinking was attributable to improved mood.
\end{abstract}

Methods-The responses of 63 participants to an exercise (aerobic workout or aerobic dance) and a "neutral" video watching condition were compared. Mood was measured using an adjective list, and creative thinking was tested by three measures of the Torrance test.

Results-Analysis of variance showed a large and significant increase in positive mood after exercise $(P<0.001)$ and $a$ significant decrease in positive mood after video watching $(\mathbf{P}<0.001)$. A significant increase between the creative thinking scores of the two conditions was found on the flexibility (variety of responses) measure $(P<0.05)$. A multifactorial analysis of all data failed to show a significant covariance of creative thinking with the two measures of mood $(P>0.05)$.

Conclusions-These results suggest that mood and creativity were improved by physical exercise independently of each other.

(Br $\mathcal{F}$ Sports Med 1997;31:240-245)

Keywords: physical exercise; mood enhancement; creative thinking

The link between physical exercise and favourable moods has now been reasonably well established. Various kinds of exercise, including especially aerobic workout, jogging/ running, bicycling, and treadmill, have been shown to enhance mood, both in anxious and depressed patients and in normal volunteers, and after both a single session and an extended exercise programme. ${ }^{1-5}$

In addition, effects on cognitive processes have increasingly been examined, but with mixed and on balance inconclusive results. Of
14 papers identified between 1981 and 1995 from a search of PsychLIT and Medline, nine reported positive findings - that is, improved cognitive performance after exercise-and five negative. ${ }^{6-10}$ The positive findings usually resulted from a running or jogging programme lasting weeks or months, ${ }^{11-13}$ although treadmill exercise $^{14}$ and dancing ${ }^{15}$ consisted of only one bout lasting 20 minutes. Some of the studies used school children and students as participants, ${ }^{13-16}$, while others used older people of 40 and above. ${ }^{11}{ }^{17} 18$ Improvements in performance were statistically significant although not usually spectacular, and measures included well known standard tasks such as alternate uses, obvious consequences, matching problems, successive and simultaneous cognitive processing tests, verbal reasoning, successive numbers tasks, digit span, and trail making. Interestingly, Hassmén et al ${ }^{19}$ reported improvements in relatively complex cognitive tasks but only if exercise was combined with the administration of branched chain amino acids, which are thought to cause decreased 5-hydroxytryptamine concentrations in the brain; however, the branched chain amino acids had little effect on mood.

In the nine "positive" investigations, mood changes did not appear to have been measured concurrently. It would have been interesting to determine how far positive moods resulting from exercise might have been related to better cognitive performance.

Mood was assessed concurrently with cognitive performance in two of the five "negative" reports, ${ }^{67}$ usually by means of adjective lists or similar self assessment methods (State-Trait Anxiety Inventory, Center for Epidemiological Studies Depression Scale, Affect Balance Scale and Cook-Medley Hostility Scale). Blumenthal $e t a l,{ }^{6}$ in a complex investigation of elderly participants, found that participants experienced some improvement in mood and showed better performance. However, these improvements were not found to be correlated with changes in aerobic power due to exercise, although greater fitness associated with reduced depression approached statistical significance, and after 14 months of participation, no significant changes in mood were found. Pierce et al also found non-significant differences between aerobic exercisers and control groups (strength training and waiting list) in improvements in mood or cognitive performance. Despite this equivocal evidence, it is widely believed, as Blumenthal et al point out, that cognitive performance is enhanced by exercise. 
It seems clear from published and unpublished case reports collected by ourselves that creative individuals, especially writers and academics, do use various forms of movement, mostly walking, to help them, especially when they are blocked. For example, a recent poem ${ }^{20}$ contains the interesting line "I walk along the beach to jog my memory". Our attention has also been drawn to Harry, the spiv, who in the 1950's film The Belles of St Trinians (with Alistair Sim), when told by the headmistress to "stop pacing about like that", replies: "I must pace-if I don't pace I can't concentrate, can't think!".

There is also considerable evidence from a large although mostly anecdotal literature that the "high" moods (hypomania as defined in $\left.D S M-I V^{21}\right)$ in manic depressive people can be most productive of creative work, ${ }^{22-25}$ although some contrasting reports have appeared-for example, that depressed moods are apt to lead to creative work and that any symptoms of mental illness are detrimental to creativity. ${ }^{26-29}$ Creativity is one of the most sought after but least understood mental processes. It is most usually defined as leading to a new product of value in the broadest sense, ${ }^{30}{ }^{31}$ and it is difficult to test quantitatively. The best known test method is the Torrance test, ${ }^{32}$ first published in 1966 and since much revised; its various components require "the subjects to think in divergent directions in terms of possibilities". The high moods in manic depressive people are usually described as feelings of intense well being, euphoria, confidence, fluency, and vigour, ${ }^{33}$ and this is similar to the descriptions of, for example, the runner's high. ${ }^{34}$ Eysenck ${ }^{25}$ has stressed the connection between psychoticism and creativity. Experimentally induced positive moods-for instance, showing a comedy film-have also been shown to facilitate creative thinking. ${ }^{35}$ Oaksford et $a l,{ }^{36}$ however, have shown that both positive and negative induced mood states can suppress some kinds of reasoning performance.

Mood has traditionally been assessed by self reports of positive and negative dimensions; most standard assessment methods have been developed against psychiatric backgrounds and have been apt to concentrate on negative aspects of mood (e.g. Profile of Mood States $\left.(\text { POMS })^{37}\right)$. However, Hendrick and Lilley ${ }^{38}$ devised a mood adjective list with a high proportion of positive items. The current list has been adapted from these two, as described in another paper. ${ }^{39}$ This list was modified from a previous investigation ${ }^{40}$ and was subjected to a principal axis factor analysis with an oblique rotation of the mood scores. The results were consistent with a primarily two dimensional structure of positive and negative effects which were relatively independent states. (For a discussion of the validity and complexity of mood scales and the status of the positivenegative dimension, see Watson et al..$^{4}$ )

Three hypotheses were tested: that aerobic exercise would lead to improved mood; that aerobic exercise would lead to improved performance in tests of creativity; that improve- ments in creativity were attributable to improved mood.

\section{Methods}

PARTICIPANTS

The participants were divided into two groups: those taking part in aerobic workouts and those doing aerobic dance. For the first group, 31 subjects, mainly students and staff at Middlesex University, were recruited by campus advertising with help from physical fitness instructors, and each was paid $£ 8.00$ for attending two sessions. There were 15 men and 16 women aged 19-54 (median age range 25-29). For the second group, 32 participants were similarly recruited, and paid $£ 7.00$ for attending two sessions. There were four men and 28 women aged 19-59 (median age range 20-24).

Participants from both groups were asked to state how much physical exercise they were involved in weekly. All exercised regularly for at least two hours a week, although this did not necessarily involve aerobics. This was an interesting but coincidental factor and not a prerequisite for selection. All participants for both experiments declared themselves to be in good health and able to participate in an aerobic exercise class. There were no drop outs.

Positive and negative mood changes were assessed, using a self completed mood adjective checklist containing 24 "positive" adjectives and 23 "negative" adjectives (see table 1) in alphabetical order and classified according to the results of a factor analysis with oblique rotation. Mood for each questionnaire was scored as total positive score and total negative score. Each individual adjective was scored on a scale of $1-5$. The purpose of the investigation to be described was to compare changes in both mood and performance of two forms of the Unusual Uses Test of Creative Thinking ${ }^{32}$ in participants who had taken part in a brief (25 minute) aerobics session, and to compare them with mood and performance changes of participants who had watched a documentary

Table 1 Mood adjective checklist containing 24 positive adjectives and 23 negative adjectives

\begin{tabular}{ll}
\hline Positive adjectives & Negative adjectives \\
\hline Active & Angry \\
Alert & Annoyed \\
Carefree & Anxious \\
Cheerful & Apathetic \\
Clear headed & Apprehensive \\
Confident & Bored \\
Contented & Detached \\
Elated & Downhearted \\
Energetic & Drowsy \\
Enthusiastic & Exhausted \\
Euphoric & Fearful \\
Friendly & Frustrated \\
Calm & Irritable \\
Happy & Lonely \\
Kindly & Mentally slow \\
Lively & Regretful \\
Pleased & Sad \\
Quick-witted & Self-absorbed \\
Relaxed & Sorry \\
Satisfied & Spiteful \\
Sociable & Suspicious \\
Stimulated & Tense \\
Sympathetic & Weary \\
Trusting & \\
\hline
\end{tabular}


style video of the rock formations of the Lake District of similar duration. The video was chosen to be, as far as possible, emotionally "neutral" but just interesting enough to hold attention.

There were thus two experiments: the first used conventional aerobic workout and the second aerobic dance. Aerobic workout was chosen because it had in previous experiments by ourselves ${ }^{39}$ and numerous others been found reliably to improve mood. This is probably best described to the lay person as high impact, and involved fast and energetic movement. It was described by the instructor as being a warm up, with exercises designed to increase mobility and coordination and raise the pulse rate (six minutes), followed by six minutes of varied routines using arm and leg movements together in order to increase stamina, and finally, a cool down, with slow relaxation stretches (five minutes). Four different music tracks accompanied the session.

Aerobic dance was chosen because at least one investigator (Gondola ${ }^{16}$ ) had reported it to be effective in improving creativity. It is best described as low impact and involved gentle exercises with a good deal of slow rhythmic stretching. It was described by the instructor as consisting of a warm up, which was repetitive exercises designed to loosen muscles in arms and legs (4.27 minutes), followed by rhythmic stretching (gentle exercises stretching different parts of the body in sequence: waist (4.12 minutes) shoulders/arms (3.35 minutes), ribs/hips (3.18 minutes) and legs (3.37 minutes)), and finally a cool down involving winding down and relaxation exercises again with the main emphasis on arms and legs (3.4 minutes). B "Sky" music tracks accompanied the exercises. The instructor was the same in both experiments, and so was the general format. It was predicted that both kinds of aerobic exercise would improve mood and, to a lesser extent, that concurrent improvements in creativity would be accounted for by the mood enhancement following exercise. Preliminary summaries have been published. ${ }^{42} 43$

\section{DEPENDENT VARIABLES}

Because the psychological effects of a single bout of exercise can be short lived, all test methods, including the creativity tests, had to be brief. Measures of mood were taken before and after each experimental session, allowing a mood change variable to be calculated-that is, mood post-exercise-mood pre-exercise. Instructions were as follows: "please indicate by placing a tick in the appropriate place, the extent to which each adjective describes how you feel at the moment. This should not take more than a few minutes, so please do not think about your response to each word and please be honest"; two to three minutes were allowed. Effects of exercise are usually shown most clearly in improvements of positive mood, ${ }^{40}$ rather than in decreases in negative aspects of mood.

Creativity was only measured post-exercise; although ideally pre-exercise creativity scores would have been helpful, their inclusion would have resulted in the counterbalancing procedures becoming too complicated and time consuming. Two forms ("Tin Cans" and "Cardboard Boxes") of Torrance's Unusual Uses Test were used. ${ }^{32}$ The instructions were: "Most people throw their empty cardboard boxes/tin cans away, but they have thousands of interesting uses. In the spaces below and on the next page, list as many of these interesting and unusual uses as you can think of. Do not limit yourself to any size of box/can. You can use as many boxes/cans as you like. Do not limit yourself to the uses you have seen or heard about; think about as many possible new ones as you can". Participants were given five minutes to complete each form of the Torrance test. There were three scores: fluency = number of responses; flexibility $=$ variety of responses - that is, shifts from one approach to another or using a variety of strategies; originality $=$ unusual uses. The number of unusual uses was expressed as the sum of ratings on a four point scale of each response. For example, listing 13 uses for a cardboard box that all involved using the box as some sort of container or shelter would score highly on fluency but have a comparatively low score for flexibility and originality. Diverse responses such as shoes, toy car, television, and shield, although less fluent, would yield higher flexibility and originality scores. Each participant completed both A and B forms of the test on separate occasions; a maximum of five minutes was allowed. Scoring was carried out independently by two experimenters, whose agreement was of the order of $r=0.89$.

\section{INDEPENDENT VARIABLE}

The independent variable was type of stimulation with two levels: exercise and television/ video watching. Participants watched a video that was chosen to be as far as possible emotionally neutral (the archaeology of the Lake District) and took part in an exercise class, both of which lasted 20-25 minutes.

\section{COUNTERBALANCING}

Participants were allocated by a random method to either a "video then exercise" or an "exercise then video" condition. Within each of these groups, half the participants completed the Tin Cans form of the Unusual Uses Test after the video, and the Cardboard Boxes test after the exercise class, and half completed the tests in reverse order.

The participants attended the experimental sessions on two consecutive days, exercising on one day and watching the video on the other. In the video condition, participants completed an initial mood scale, and then watched the video for 25 minutes. They then completed the mood scale again, and finally the Unusual Uses Test. The 25 minute exercise condition was similar. The standardised written instructions for each test were supplemented with a verbal reinforcer of the points made on the printed instruction sheets. 


\section{Results}

The original intention of this study had been only to use aerobic workout as described above. However, because of the relatively small differences on the three measures of creativity between the two groups and the fact that aerobic workout requires a good deal of energy, concentration, and coordination, which might detract from any beneficial cognitive effects, it was decided to use a comparable but less complex and gentler form of aerobic exercise (aerobic dance ${ }^{16}$ ) for the second experiment. Although there may have been physiological differences in the two types of exercise, mood and creativity scores did not differ significantly; there was little difference from the results obtained by the analysis of the combined scores, and the sample sizes of 31 and 32 became too small to be meaningful. It was therefore decided to combine the two data sets.

No significant differences were found between the two demographic variables (age and sex) on any of the measures used.

Total positive and negative mood scores were computed from all initial questionnaires, and, when results were analysed separately for each of the two experiments, they yielded baseline results comparable with those obtained overall.

\section{EXERCISE AND MOOD}

Two repeated measures $t$ tests were used to assess differences in mood after exercise (fig 1). As predicted, a significant increase in positive $\operatorname{mood}(t(63)=5.04, P<0.001)$ and decrease in negative mood $(t(63)=-4.04, P<0.001)$ was observed for the two experiments combined These results were mirrored in the analyses of the individual experiments as follows: aerobic workout: positive mood $(t(31)=5.48$, $\mathrm{P}<0.001)$ and negative $\operatorname{mood}(t(31)=-3.47$, $\mathrm{P}<0.001)$; aerobic dance: positive mood $(t(32)$ $=5.28, P<0.001)$ and negative $\operatorname{mood}(t(32)=$ $-4.57, \mathrm{P}<0.001)$

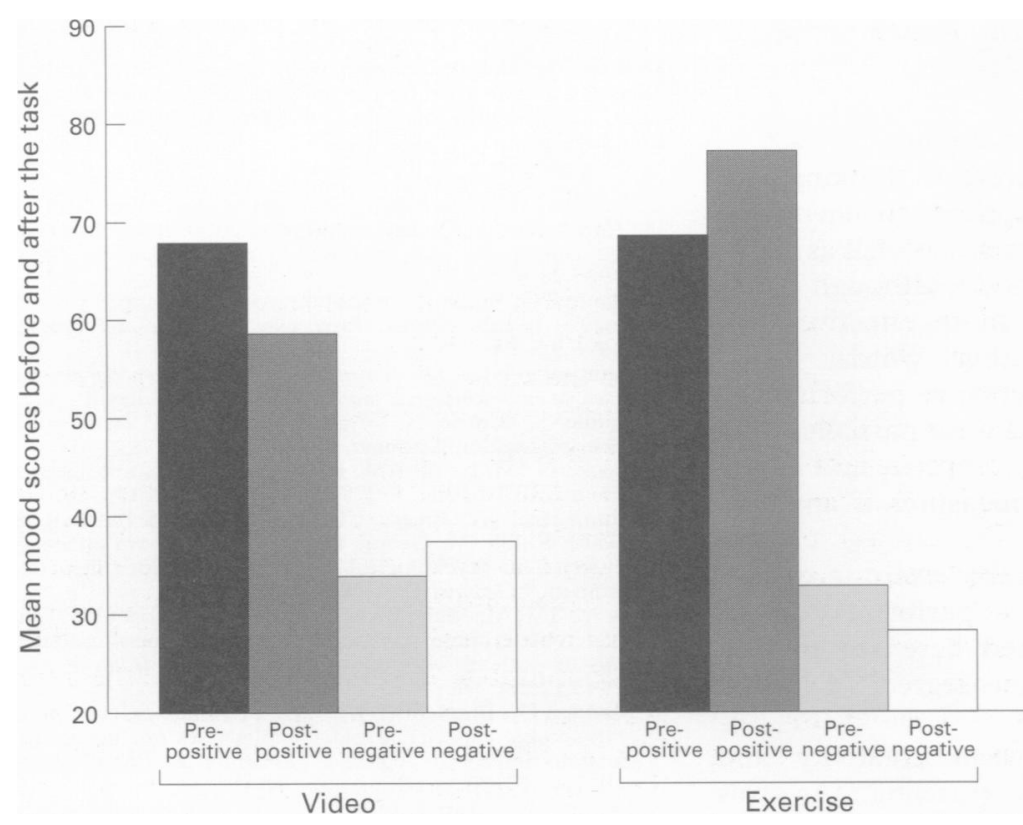

Figure 1 Mean positive and negative mood scores before and after the task. Positive mood increased after exercise and decreased after video watching $(P<0.001)$; negative mood decreased after exercise and increased after video watching $(P<0.001)$
EXERCISE, VIDEO, AND MOOD

The aim of including the video task was to assess the effects of exercise on creativity relative to a television watching activity for a similar period in the presence of the same participants. If mood did account for an increase in creativity after exercise, but watching the video did not, then a significant interaction effect would be found on the mood ratings between exercise and video before and after the task. To test for this effect, a two way repeated measures analysis of variance was used for each of the two measures of mood. A significant main effect of type of leisure activity was found on the positive mood variable $(F(1,62)=$ $37.16, \mathrm{P}<0.001)$. This effect can be explained by the predicted interaction effect $(F(1,62)=$ $58.21, P<0.001$ ). In summary, positive mood increased after the exercise condition and decreased after the video condition (see fig 1).

An approximately converse pattern of results was found for the negative mood variable with a significant main effect of type of leisure activity $(F(1,62)=19.96, \mathrm{P}<0.001)$ accounted for by the overall interaction effect $(F(1,62)=$ 32.62, $\mathrm{P}<0.001)$. Thus negative mood decreased after exercise and increased after watching the video (see fig 1 ).

EXERCISE, VIDEO, AND CREATIVITY

Previous research described in the introduction has shown improvements in creativity after exercise, as measured by divergent thinking tasks. It was therefore expected that the participants would perform better on the divergent thinking task after exercise. Repeated measures $t$ tests were used to assess the differences on three aspects of divergent thinking: fluency, flexibility, and originality. Although the participants obtained better scores on the fluency measure after exercise (fig 2), the difference between exercise and video watching was not statistically significant $(t(63)=1.46$, $P>0.05)$. A significant improvement was, however, found on the flexibility measure $(t(63)=$ $2.25, \mathrm{P}<0.05)$. Finally, the participants scored worse on the originality measure after exercise. However, this difference was marginal and non-significant $(t(63)=-0.46, \mathrm{P}>0.05)$.

\section{MOOD, EXERCISE, AND CREATIVITY}

Although only one of the three measures of divergent thinking produced significant differences between the exercise and video conditions, it was decided that an analysis of covariance would be used on all three measures to test the final hypothesis, which stated that improvements in divergent thinking after exercise could be explained by an increase in positive mood and a decrease in negative mood. All three analyses failed to show a significant covariance with the two measures of mood: fluency $(F(2,60)=0.41, P>0.05)$; flexibility $(F(2,60)=0.20, P>0.05) ;$ and originality $(F(2,60)=2.62, \mathrm{P}>0.05)$, and, if anything, creativity increased when mood was partialled out. Similarly, calculations of correlation coefficients showed no relationship between improvements in mood and creativity. In summary, it can therefore be tentatively concluded 


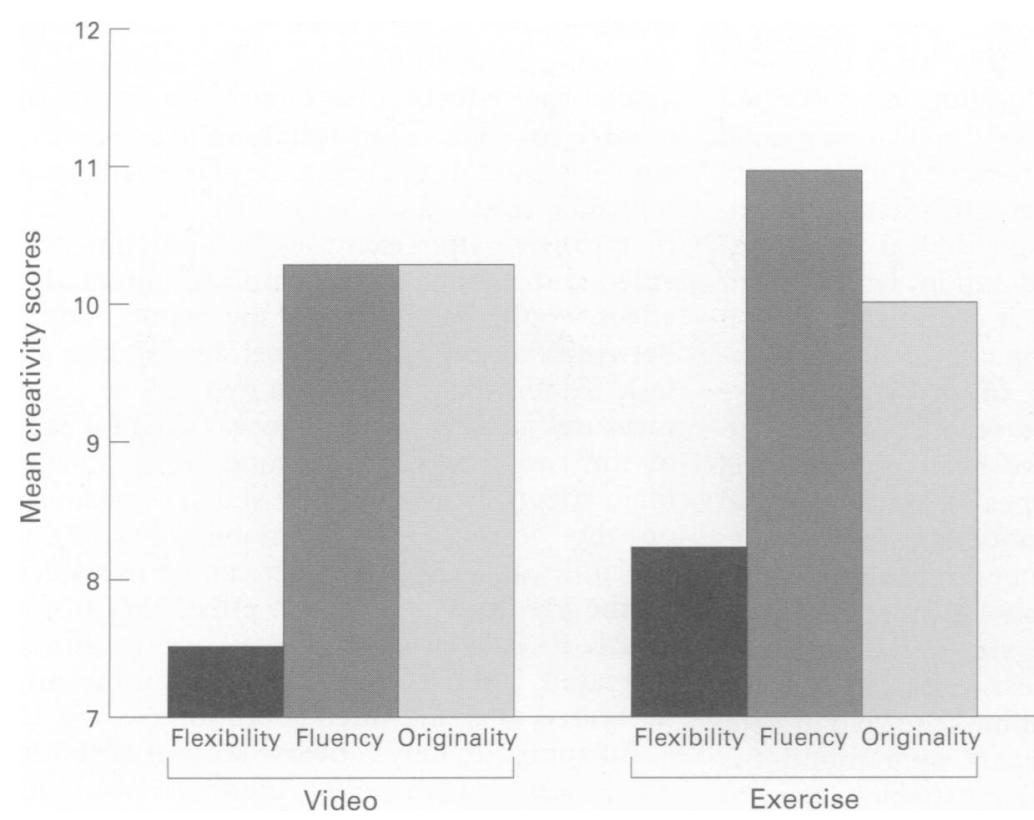

Figure 2 Mean scores on three measures of divergent thinking after exercise and video watching. The difference in mean flexibility scores is statistically significant $(t(63)=2.25$, $P<0.05)$.

that mood did not account for increases in creativity after exercise.

\section{Discussion}

The results of this investigation show that mood was significantly improved (by around $25 \%, P<0.001)$ by two kinds of aerobic exercise (workout and dance) lasting only 25 minutes, as compared with a neutral video control group, and that there was a consistent although modest increase in at least one measure of creativity assessed by two parallel forms of the Unusual Uses Test, which is part of the Torrance test of creative thinking. Even where differences in Torrance test performance were not statistically significant, two thirds were in the predicted direction of improvement, namely flexibility and fluency, while originality worsened. In particular, one might have expected fluency to have shown a bigger positive effect, since this is especially characteristic of hypomania.

Physical exercise can therefore be said to have slightly enhanced creative thinking, but the effect, surprisingly, appears to have been independent of mood changes as well as of the kind of aerobic exercise used, although dance was perhaps marginally more effective than aerobic workout. In other words, mood changes did not predict creative performance; when the effects on mood were partialled out, the differences between exercise and video effects on the creativity measures if anything increased.

Although therefore aerobic exercise can be used to enhance creative performance, the consequences as measured here are modest and not related to the degree of mood improvement.

The dissociation between creativity and mood after exercise is puzzling. As was indicated in the introduction, the existing literature is of little help in explaining this. It may be that the improvements in mood in this investigation were not great enough to markedly facilitate creative thinking, as happens in hypomania.

It is also possible that running, which has most strikingly led to enhanced moods (e.g. ${ }^{39}$ ), would have been a more suitable form of exercise for the present purpose, although again, previous literature throws little light on this. It may be that "free" rather than prescribed exercise is more likely to release the "stream of consciousness", as we ourselves have found in pilot experiments; but we found it difficult to persuade subjects to carry out free exercises. The slightly greater improvements in creativity after aerobic dance could possibly be due to the nature of the exercise, which allows more freedom of movement than the regimented aerobic workout. Or else it may be that longer exercise bouts are required for better effects on creativity. Although previous research ${ }^{12}{ }^{15}$ has looked at both short and long term effects of aerobic exercise, the lengths of the sessions have been similar. Possibly, more sensitive tests of creativity are needed; but as far as we can tell no other suitable short test is available. The exercise history of the participants is also likely to be relevant. Tomporowski and Ellis ${ }^{45}$ suggest that regular exercisers expect exercise to have beneficial effects on mood and cognitive abilities; consequently any results may be biased by motivational factors. Perhaps future research should, in addition to the mood factor, examine other robust exercise effects such as self esteem and "arousal" changes as predictors of increased cognitive activity after exercise, or perhaps habitual and inexperienced exercisers should be compared. It is also possible that exercise increases creativity directly, without the intervention of mood changes, although again, the published literature is of little help. Once the various contributory factors have been identified and "titrated" it should be possible to develop exercise programmes that have greater benefits for cognitive performance.

We thank the Wolfson Foundation for support, Janie Turnbull the aerobics instructor, for her cooperation, Malcolm Hart for statistical advice and computing, and Professor Craig Sharp for lively suggestions.

1 Steinberg H, Sykes EA. Introduction to Symposium on Endorphins and Behavioural Processes: review of literature on endorphins and exercise. Pharmacol Biochem Behav 1985;23:857-62.

2 Plante TG, Rodin J. Physical fitness and enhanced psychological health. Current Psychology: Research and Reviews 1990;9:3-24.

3 Seraganian $\mathrm{P}$ (ed). Exercise psychology: the influence of physical exercise on psychological processes. New York: Wiley, 1990.

4 Biddle S, Mutrie N. Psychology of physical activity and exercise. London: Springer, 1991.

5 Cockerill IM, Nevill AM, Byrne NC. Mood, mileage and the menstrual cycle. Br $\mathcal{F}$ Sports Med 1992;26:145-50.

6 Blumenthal JA, Emery CF, Madden DJ, Schniebolk S, Walsh-Riddle M, George LK, et al. Long-term effects of exercise on psychological functioning in older men and exercise on psychological function
women. $\mathcal{F}$ Gerontol 1991;46:352-62

7 Pierce TW, Madden DJ, Siegel WC, Blumenthal JA. Effects of aerobic exercise on cognitive and psychosocial functionof aerobic exercise on cognitive and psychosocial functioning in patients

8 Madden DJ, Blumenthal JA, Allen PA, Emery CF. Improving aerobic capacity in older adults does not necessarily lead to improved cognitive performance. Psychol Aging 1989;4:307-20

9 Lawless WF. Effect of arousal on mathematics scores. Percept Mot Skills 1988;67:318.

10 Blumenthal JA, Maddem DJ. Effects of aerobic exercise training, age and physical fitness on memory search performance. Psychol Aging 1988;3:230-85. 
11 Ismail AH, El-Naggar AM. Effect of exercise on cognitive processing in adult men. $f$ Hum Ergol (Tokyo) 1981;10:8391 .

12 Gondola JC, Tuckman BW. Effects of a systematic program of exercise on selected measures of creativity. Percept Mot of exercise on selected

13 Tuckman BW, Hinkle JS. An experimental study of the physical and psychological effects of aerobic exercise on school children. Health Psychol 1986;5:197-207.

14 Zevras Y, Danis A, Klissouras V. Influence of physical exertion on mental performance with reference to training. Percept Mot Skills 1991;72:1215-21.

15 Gondola JC. The enhancement of creativity through long and short term exercise programs. Fournal of Social Behaviour and Personality 1986;1:77-82.

16 Gondola JC. The effects of a single bout of aerobic dancing on selected tests of creativity. Fournal of Social Behaviour and Personality 1987;2:275-8.

17 Clarkson-Smith L, Hartley AA. Relationships between physical exercise and cognitive abilities in older adults. Psychol Aging 1989;4:183-9.

18 Clarkson-Smith L, Hartley AA. Structural equation models of relationships between exercise and cognitive abilities. Psychol Aging 1990;5:437-46.

19 Hassmén P, Blomstrand E, Ekblom B, Newsholme EA Branched chain amino acid supplementation during 30-km competitive run: mood and cognitive performance Nutricompetitive run: mood

20 Adcock F. Labour of love. Sunday Times, Style 1995; December 10:8.

21 Diagnostic and statistical manual of mental disorders (DSMIV), 4th ed. Washington, DC: American Psychiatric Association, 1994.

22 Greene TR, Noice $H$. Influence of positive effect upon creative thinking and problem solving in children. Psychol Rep 1988;63:895-8.

23 Richards R, Kinney DK. Mood swings and creativity. Creativity Research fournal 1990;3:202-17.

24 Richards R, Kinney DK, Daniels H, Liskins K. Everyday creativity and bipolar and unipolar affective disorder: preliminary study of personal and family history. European preliminary study of personatry 1992;7:49-52.

25 Eysenck HJ. Genius: the natural history of creativity. Cambridge: Cambridge University Press, 1995.

26 Andreasen ND, Glick ID. Bipolar affective disorder and creativity: implications and clinical management. Compr creativity: implications and

27 Eisenman R. Creativity, preference for complexity, and physical and mental illness. Creativity Research fournal 1990;3:231-6.

28 Slaby AE. Creativity, depression and suicide. Suicide Life Threat Behav 1992;22:157-66.

\section{Commentary}

If the sport and exercise sciences were ever asked to agree on a corporate slogan then a front runner undoubtedly would be "mens sane in corpore sano". Indeed, many seem to support this sentiment with a zeal that borders on the fanatical, and that can cloud the execution of a reasoned evaluation of the precise psychological benefits accruing from exercise.

Hannah Steinberg and her coworkers are to be encouraged for adding to a growing literature that at long last is prepared to acknowledge the complexity of the relation between psychological wellbeing and physical exercise. To develop this debate the first step must be a disaggregation of both the "mens" and the "corpora"- that is, which types of physical exercise (for example, aerobic or anaerobic, maximal or submaximal, massed or
29 Ludwig AM. Creative achievement and psychotherapy: comparison among professions. Am $\mathcal{F}$ Psychother 1992;42: 307-20.

30 Weisberg RW. Creativity: beyond the myth of genius. New York: W H Freeman, 1992.

31 Boden M. Dimensions in creativity. London: MIT Press, 1994.

32 Torrance PE. Torrance tests of creative thinking. New Jersey: Personnel Press, 1966

33 Jamison KR. Touched with fire: manic depressive illness and the artistic temperament. New York: Free Press, 1993

34 Sachs ML, Buffone GW. Running as a therapy: an integrated approach. London: University of Nebraska Press, 1984.

35 Isen AM, Daubman KA, Nowicki GP. Positive effect facilitates creative problem solving. $\mathcal{f}$ Pers Soc Psychol 1987;6: $1122-31$.

36 Oaksford M, Morris F, Grainger B, Williams JMG. Mood reasoning and central executive processes. $f$ Exp Psychol Learn Mem Cogn 1996;22:476-92.

37 McNair DM, Lorr M, Droppleman LF. Psychological effects of acute physical activity. Arch Phys Med Rehabil 1971;52:422-5.

38 Hendrick C, Lilley RS. Self-reported mood and running under natural conditions. Work and Stress 1970;7:161-77.

39 Steinberg H, Sykes, EA. Mood enhancement through physical exercise. In: Shroder H, Reschke K, Johnston M, Maes $\mathrm{S}$, eds. Health psychology, potential in diversity. Regensburg Roderer Verlag, 1993.

40 Steinberg H, Salmon P, Morris M. The "runner's high": dimensions of mood states after running. In: Proceedings of sport, health, psychology and exercise symposium 88. London Sports Council and Health Education Authority, 1990 147-52.

41 Watson D, Clark LA, Tegellen A. Development and validation of brief measures of positive and negative effect: the PANAS scales. $\mathcal{F}$ Pers Soc Psychol 1988;6:1063-70.

42 Sykes EA, LeBoutillier N, Moss T, Steinberg H. Dissociation between improvement of mood and creativity following exercise. The British Psychological Society Sport and Exercise Psychology Section Newsletter 1995;4:5-7.

43 Sykes EA, LeBoutillier N, Moss T, Steinberg H. Dissociation between improvement of mood and creativity tollowing exercise [abstract]. British Psychological Society Annual Conference 1995;3:133.

44 Morris M, Steinberg H, Sykes EA, Salmon P. Temporary withdrawal from regular running. F Psychosom Res 1990;34: 493-500.

45 Tomporowski PD, Ellis RN. Effects of exercise on cognitive processes: a review. Psychol Bull 1986;99:338-46.

distributed, short or long term) are related to which cognitive and affective functions. As this paper and previous work ${ }^{1-3}$ show there are no simple answers here, complexity is writ large. Hence further empirical work of this nature is vital to add to our uncertainty before we can start to piece together the psychological, physiological, and contextual components of this fascinating jigsaw.

JOHN KREMER

Reader in psychology

The Queen's University of Belfast

1 McMurray RG. Exercise, mood states and neuroendocrinology. In: Diamant L, ed. Mind-body maturity, psychological approaches to sports exercise and fitness. New York: Hemisphere, 1991:237-54.

2 North TC, McCullagh P, Tran ZV. Effect of exercise on depression. Exerc Sport Sci Rev 1990;18:379-415.

3 Willis JD, Campbell LF. Exercise psychology. Champaign, IL: 